\title{
PERFIL DAS CRIANÇAS SUBMETIDAS À AMIGDALECTOMIA E/OU ADENOIDECTOMIA EM UM HOSPITAL GERAL DE TAUBATÉ-SP
}

\author{
Tais Maria Candido Marcondes ${ }^{1}$ \\ Patrícia Basso de Oliveira ${ }^{2}$ \\ Sergiane Langanke Mariano ${ }^{3}$ \\ Valéria Celestina Volpi Oliveira ${ }^{4}$ \\ Teresa Celia de Mattos Moraes dos Santos ${ }^{5}$ \\ Eliana Fatima de Almeida Nascimento ${ }^{6}$ \\ Ana Lucia De Faria ${ }^{7}$
}

\begin{abstract}
Resumo: As amígdalas são conhecidas como tonsilas palatinas estão localizadas na orofaringe e as adenóides como tonsilas faríngeas, localizadas atrás das fossas nasais. Objetivo: Identificar o perfil clínico e cirúrgico das crianças submetidas a amigdalectomia e/ou adenoidectomia em um hospital de Taubaté SP. Método: Pesquisa retrospectiva e quantitativa. Resultados: Foram pesquisados 361 prontuários. A faixa etária, foi de 4 a 7 anos em 32,32\%, sexo masculino em 50,42\%; a indicação cirúrgica foi hipertrofia adenoamigdaliana em 85,04\%; o ronco prevaleceu em 32,03\% e a inflamação da garganta, em 45,54\%, cirurgia de adenoamigdalectomia em 85,04\%, tempo de cirurgia foi de 0-20 minutos em 60,94\%, tempo de internação de 16h-20h em 37,67\%. Conclusão: o perfil das crianças foi de 4 a 7 anos de idade; masculino; com hipertrofia adenoamigdaliana; cirurgia adenoamigdalectomia; período de internação de $16 \mathrm{~h}$ a $20 \mathrm{~h}$ e com ausência de complicações.
\end{abstract}

Palavras-chave: Enfermagem; Cirurgia; Complicações.

\footnotetext{
1 Ciências da Saúde/UNITAU, Brasil, E-mail: taisevidencia.pinda@hotmail.com.

2 Ciências da Saúde/UNITAU, Brasil, E-mail: patriciabasso19@gmail.com.

${ }^{3}$ Ciências da Saúde/UNITAU, Brasil, E-mail: lenf.serg@gmail.com.

${ }^{4}$ Ciências da Saúde/UNITAU, Brasil, E-mail: lelavolpi@gmail.com

${ }^{5}$ Ciências da Saúde/UNITAU, Brasil, E-mail: teresacelia@terra.com.br.

${ }^{6}$ Ciências da Saúde/UNITAU, Brasil, E-mail: efanascimento@yahoo.com.br.

7 Ciências da Saúde/UNITAU, Brasil, E-mail: anadinda2002@yahoo.com.br.
} 